\title{
Function of Social Cohesion Element in Participatory Empowerment towards Landless Peasants
}

\author{
Dumasari Dumasari ${ }^{1}$, Budi Dharmawan ${ }^{2}$, Imam Santosa ${ }^{3}$, Wayan Darmawan ${ }^{\square}$, Dinda \\ Dewi Aisyah $^{3}$, and Sulistyani Budiningsih ${ }^{3}$ \\ ${ }^{1}$ Faculty of Agriculture, Purwokerto Muhammadiyah University, Purwokerto, Indonesia \\ ${ }^{2}$ Faculty of Agriculture, Jenderal Soedirman University, Purwokerto, Indonesia \\ ${ }^{3}$ Faculty of Social and Political Sciences, Jenderal Soedirman University, Purwokerto, Indonesia
}

\begin{abstract}
Abstract. Social cohesion is one of the essential elements in participatory empowerment of landless peasants. This study aims to examine the categorization function within elements of social cohesion in empowering landless peasants using a participatory manner. The research location was set intentionally in Baturaden District, Banyumas Regency and Purbalingga Wetan Subdistrict, Purbalingga Regency, Central Java Province, Indonesia. The research method is using an intrinsic case study approach. Based on the research result showed that the predominant function within elements of social cohesion at the individual level are enthusiasm, trust, quality and closeness of social relations, solidarity and social values, while some element of social cohesion at the community level has a function towards peasant participatory in the empowerment include motives, mentality, actions, behavior, awareness of self-identity and morality. Lastly, the quality of social relations and collaboration networks is a manifestation of social cohesion which has a dominant function at the institutional level. All elements of social cohesion function are reinforcing energy and driving the activeness of landless peasant in participatory empowerment.
\end{abstract}

\section{Introduction}

Land scarcity is one of the urgent and crucial issues in the dynamic agricultural development area which has a sustainable and environmentally friendly characteristic. Conversion of agricultural land into non-agriculture land is a dilemma because on the one hand it benefits investors with businesses outside of agriculture and on the other hand, it harms the peasants and agricultural enterprises [1]. The land conversion rate is difficult to control, so it threatens the peasants to become a landless peasant [2]. The number of landless peasants has increased steadily over time. Landless peasants are prone to the poverty traps because of their status, which shifts from peasant landowners to farm laborers. The scarcity of land due to conversion is closely related to poverty [3]. Land 
conversion also impedes sustainable agricultural development [4]. Landless peasants face various challenges, including the difficulties in getting the job opportunities and social security [5].

The right of farmworkers to arable land is not optimal because the landowners determine all decisions and actions. Farmworkers only work on a plot of the farm owned by someone else and are given daily or weekly wages according to the agreement. Some farmworkers are not blown but get the harvest share. It is not uncommon for peasants to leave work on-farm and switch to off-farm or non-farm. Transfer of work is not easy for peasants. The habit of adopting an agrarian culture made it difficult for farmworkers to accept the urban-industrial culture. Landless peasants who transfer their livelihoods are prone to experiencing cultural shock. Land scarcity tends to occur in lowland rice peasants who act as food producers. If it is allowed to continue, a series of problems with peasants tend to create complex problems. Agricultural land conversion is not only trapped the farmworkers into the poverty cycle but also encourages the urbanization and reduces national food production [6, 7, 8]. The Government of the Republic of Indonesia has mobilized landless peasants in various participatory empowerment activities. Empowerment theory has broad insight into individual and collective behavior related to active participation in changing and forming social-environmental contexts [9]. The focus of participatory empowerment activities lies in developing diversified creative, productive livelihoods. Livelihood diversity has a positive and significant impact on income. Diversification is a strategy for peasants who are proactive in choosing the types of jobs available such as progressive diversification [10]. Diversification of products on a farm reduces marginal effects along with the income distribution of peasants, including landless peasants.

Landless peasants can have an entrepreneurial spirit, especially in developing business on-farm, off-farm and sustainable non-farm as the producers of honey, animal fodder, processed fruit, souvenirs or handicrafts, wood fuel, processed fruit, and livestock products $[11,8,12]$. However, it is known that peasants in the rural areas are difficult to be actively mobilized in participatory empowerment.

One strategic solution to mobilizing landless peasants in participatory empowerment is through the use of elements of social cohesion. The limits of the concept of social cohesion are not only included the in participation but also broaden the emphasis of this behavior to include the idea of trust, connectedness, and community involvement, including peasants' persuasion [9]. Various elements of social cohesion of collectivity, solidarity, value, social norms, tolerance, caring, self-identity, networks of cooperation, reciprocity, social control have essential functions for the smooth participation of empowerment. Social cohesion is strong energy to awaken the sense of togetherness of landless peasants to decide to act actively in participatory empowerment.

Based on the essential values of social cohesion encourage the selection of research themes. A significant theme is the empowerment of agricultural communities based on local resources. Social cohesion as a collective product of landless peasant needs to be studied in-depth to reveal its contribution to the awareness, motivation, and ability of active peasants in participatory empowerment. Selected themes are relevant to developing the capacity of peasants to be able to be independent and produce appropriately in the social, economic, and environmental fields.

\section{Material and Methods}

The research design about an element function of social cohesion for landless peasants' empowerment in a participatory manner use intrinsic case study with qualitative and quantitative approach [13]. A qualitative approach is useful for completing the depth and 
detail of the data. A qualitative approach helps researchers to understand the subject's personal experience from the point of view concerned. A qualitative approach keeps researchers from being trapped in stereotypically rigid theoretical thinking. The quantitative approach is intended to reveal the categorization of elements of social cohesion. A qualitative approach is appropriate to examine the relevance of the functions of social cohesion to participatory empowerment. Researchers use social reality in the field to explain holistically and deeply about the diversity of functions of elements of social cohesion that determine participatory empowerment of peasants. Realization of speech, deeds, and actions of landless peasants are the data which has been observed and analyzed during the research.

The ethical approach and the emic approach are utilized in the formulation of the reconstruction result of the participatory empowerment concept. The ethical approach is directed towards meeting data sourced from the researcher's perspective. The emic approach used to uncover data from landless peasants.

Determination of the location of the study was carried out by purposive area in Baturaden Subdistrict, Banyumas Regency and Purbalingga Wetan Subdistrict, Purbalingga Regency, Central Java Province. Both of these sub-districts were chosen based on the consideration of the majority of the people patterned as livelihoods as landless peasants (farm workers). The average peasant income level is IDR 650,000 per month. Landless peasants follow the participatory empowerment but still slow because of weakened social cohesion. The problems in the two sub-districts were chosen because of the relevance to the research theme.

The subject of the population included all farmers who experienced poverty in the two study locations. Determination of respondents as a quantitative primary data source using purposive sampling technique, while informants as qualitative primary data sources were selected by the snowballing technique. The number of primary data sources is not strictly determined but tend to based on consideration of the needs and completeness of the data.

Data collection techniques used were in-depth interviews, participant observations, focus groups discussions, and documentation analysis. All qualitative data collected is processed through a sequence of steps: writing data, editing data, classifying similar data, reducing data, tracing data on themes, and linking themes and presenting data. Processing and analysis of qualitative data is done while in the field (ongoing analysis). Qualitative data analysis techniques use the Interactive Model [14]. Quantitative data were analyzed by descriptive statistics with scoring values, tabulation, frequency distribution, and percentage values.

\section{Result and Discussion}

Social cohesion in landless peasants has an essential function in increasing participation in participatory empowerment. The social cohesion inherent in the respondents is divided into three interrelated levels. These three levels are individuals, society, and institutions. Social cohesion at the community level most strongly contributes to the intention, enthusiasm, willingness, and ability of respondents to be active in participatory empowerment. The enticement of social cohesion is indeed strong at the community level to respondents so that they are active in managing business on-farm, offfarm and non-farm. The social reality is closely related to social values and norms that are based on collectivity and the identity of socio-economic status as landless peasants. The gemainschaft social bond connects the existence of respondents. Respondents tended to follow something that has been done by other community members in the majority $(>50$ percent). Landless peasants have a lack of the courage to act in connection with empowerment activities. A technology for spacing setting with a legowo pattern is adopted 
if the majority ( $>50$ percent) of a large number of landless peasants have applied for morning farming in monoculture fields. The actions and decision-making of respondents are determined by agreement.

Social cohesion at the weak individual level encourages respondents to participate in various participatory empowerment activities actively. Respondent awareness is slow because independence is classified as low in determining decisions and actions. Social cohesion in the respondent seemed to fall asleep until he was often unaware of the importance of participatory empowerment — the dominant level of social cohesion influences decision making and specific actions for community social activities.

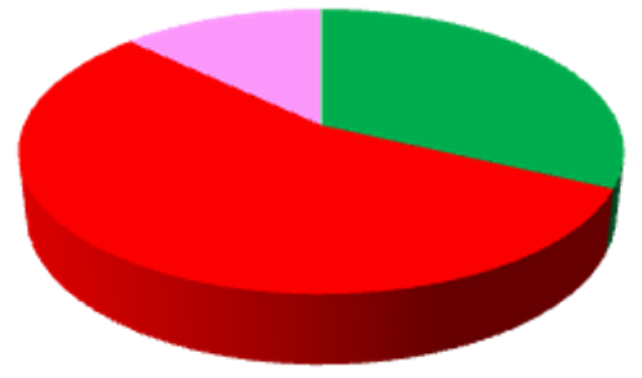
- Social cohesion at the individual level
- Social cohesion at the community level
Social cohesion at the institutional level

Fig 1. Contribution of the social cohesion function to landless peasant participatory empowerment

The ability of social cohesion at the institutional level is classified as weak in motivating respondents to be active in various participatory empowerment activities. Various institutional forms in the midst of the social structure of peasants who are less able to mobilize respondents' awareness of the strategic value of participatory empowerment. Innovations about the technology of processing corn crops into cornstarch delivered through the social gathering (arisan) of women peasants in the village took place slowly. Only a few (16 percent) of respondents participated in the trial. The institutional weaknesses that are less able to take advantage of social cohesion as a driver of landless peasants due to the far social distance and heterogeneous social levels. The condition of the function of social cohesion at the individual, community, and institutional level in contributing support to participatory empowerment in respondents was observed in Figure 1.

Social cohesion has an element that serves as an adhesive to the closeness of fellow respondents. Elements of social cohesion are at the level of individuals, communities, and institutions. The various elements of social cohesion at each level have similarities and differences. The condition of the elements of social cohesion before and after participatory empowerment shows different levels of functioning at each level. Respondents made adjustments to the elemental functions of social cohesion. Adjustments occur at each level during participatory empowerment.

The function in some elements of social cohesion within respondents is still weak especialy at the individual level. The weak condition of the function occurs before participatory empowerment takes place. Respondents were less eager to increase productivity and creativity. The respondent's attitude was surrendered and was willing to accept a limited situation due to the status of the charity. The respondents' mentality is weak, so they are reluctant to receive information about production technology, postharvest technology, and packaging techniques for participatory empowerment. Respondents rarely attend training sessions, counseling, group discussions, socialization, and demonstrations on ways. Trust weakened, and there was a suspicion of productive actions carried out by other craftsmen. The quality of social relations is terrible due to economic activities 
because there is a sense of competitiveness, jealousy, and suspicion. With some weakening elements of social cohesion, the function of the element of social control has also been reduced. Respondents carry out economic activities according to their abilities and are individualistic. The function of the element of strong social cohesion at the individual level is only in social activities in the community.

The function of elements of social cohesion at the individual level has increased and decreased after respondents actively participated in participatory empowerment. The most dominant spirit element has increased function. Respondents have the enthusiasm to develop productive businesses on-farm after post-harvest. Increased enthusiasm occurred after respondents learned the benefits of agricultural processed products that have added value. Trust among respondents who are active in participatory empowerment is increasing. A sense of competitiveness, jealousy, and suspicion are pressured until the quality of social relations improves among fellow respondents with other peasants. The function of respondent's solidarity element increases because there is a network of cooperation to help each other in providing information on technology, prices, and markets.

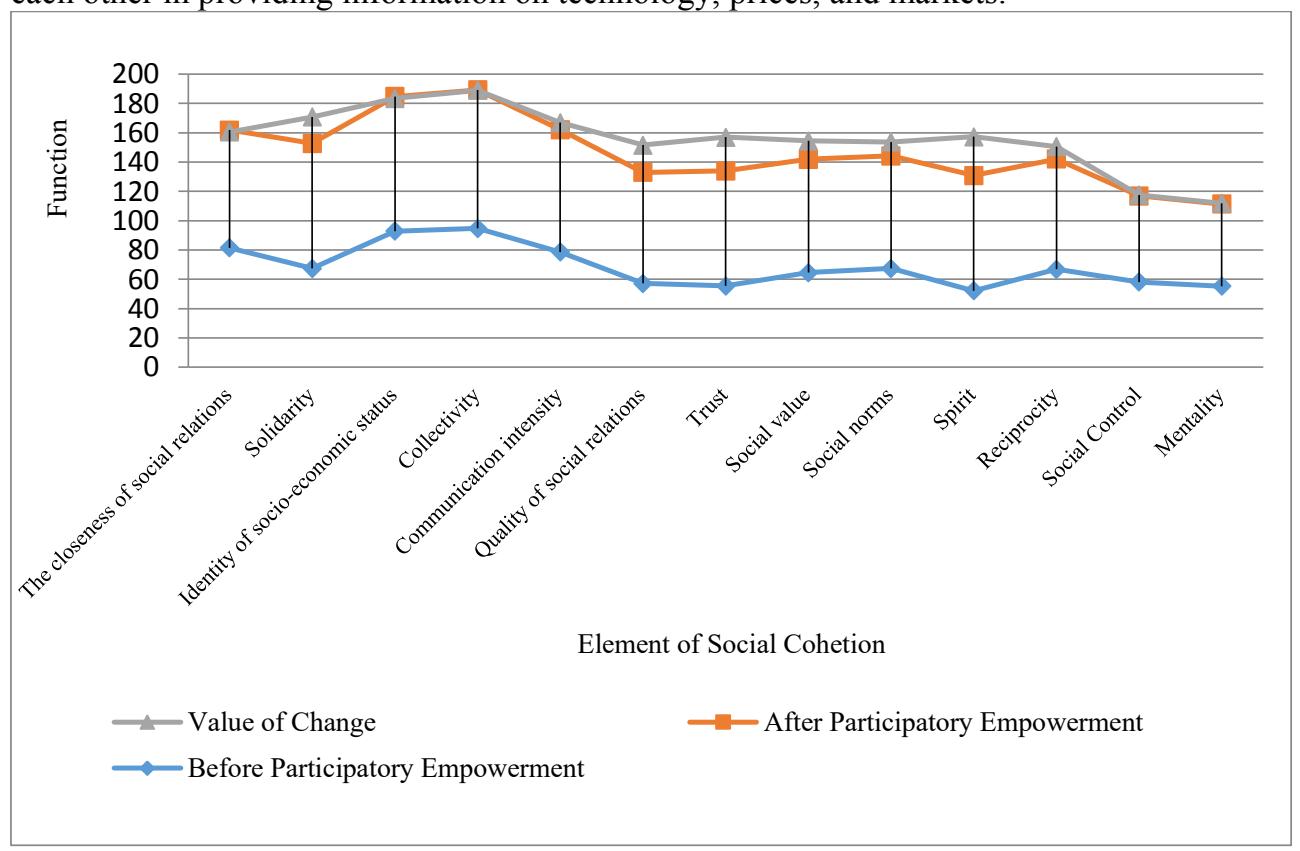

Fig 2. The function of elements of social cohesion at the individual level

Other elements that experience increased function are social norms and reciprocity. The element of social cohesion which has decreased function is the closeness of social relations and the identity of socio-economic status. Respondents claimed that after participating in participatory empowerment the forms of unproductive entertainment, social relations had been diminished. The identity function of the socio-economic status of landless peasants has eroded because the landless peasants have been able to continue farming with verticulture and aquaculture technology on a narrow yard. The function of individual-level social cohesion elements is shown in Figure 2.

Social cohesion at the community level has several elements that function important to the ability of respondents to actively participate in participatory empowerment. All elements of social cohesion have proper functions at the community level. The respondent's mentality element is not strong enough to bear the position of being squashed as a steadystate peasant when he has not participated in participatory empowerment. Motive function for productive and creative activities is low. Respondents only pursue temporary jobs that 
are as farm laborers, building laborers, small industrial workers, transport workers, and motorcycle taxi drivers, janitors, parking attendants, and security officers. Respondents only surrender to accepting any work to earn daily income. The function of self-action is limited only to subsistence economic activity. The function of the elements of social cohesion concerning community activities tends to be active even though respondents have not actively participated in participatory empowerment.

The elemental functions of mentality, motives, and actions of respondents experienced a significant increase after being active in participatory empowerment. The courage to start a new product business of on-farm, off-farm, and non-farm appears even slowly. Respondents manage farming vegetables and freshwater fish ponds with aquaponic technology on the home page. Some also started raising chickens and goats. Off-farm work is being developed, which is producing various foods and beverages sold around the village. Even so, the function of several elements of social cohesion has experienced a real setback after participatory empowerment. Some of these elements include adaptation, tolerance, and solidarity. The function of caring and empathy also experiences setbacks because respondents are busy managing productive businesses and feel increasingly accustomed to improved economic conditions. Therefore the respondent's empathy towards subsistence is reduced.

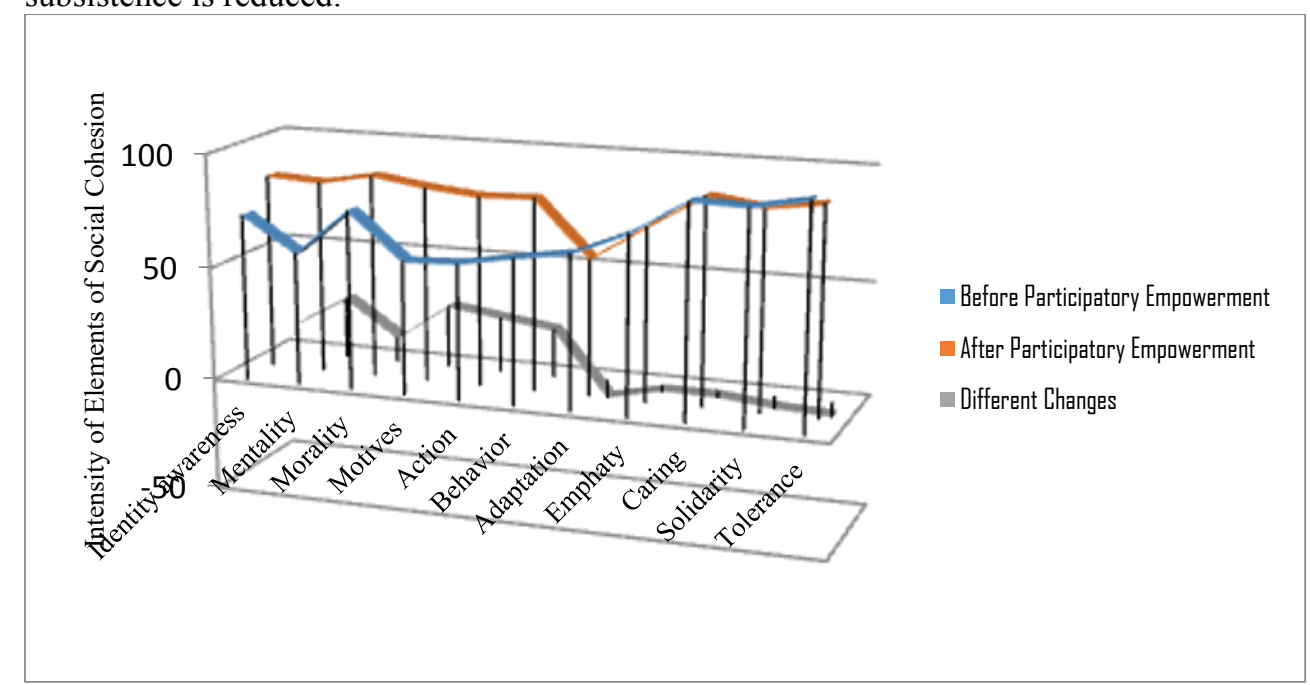

Fig 3. The function of social cohesion elements at the community level

Changes in the function element of social cohesion that took place at the community level show the attachment of the respondents in the collectivity of landless peasants is high. Empowerment carried out collectively, is easier to mobilize awareness, motivation, and ability as well as the willingness of active respondents, especially in developing diversified productive livelihood activities. The function of various elements of community-level social cohesion to participatory empowerment of smallholder peasants is detailed in Figure 3. 


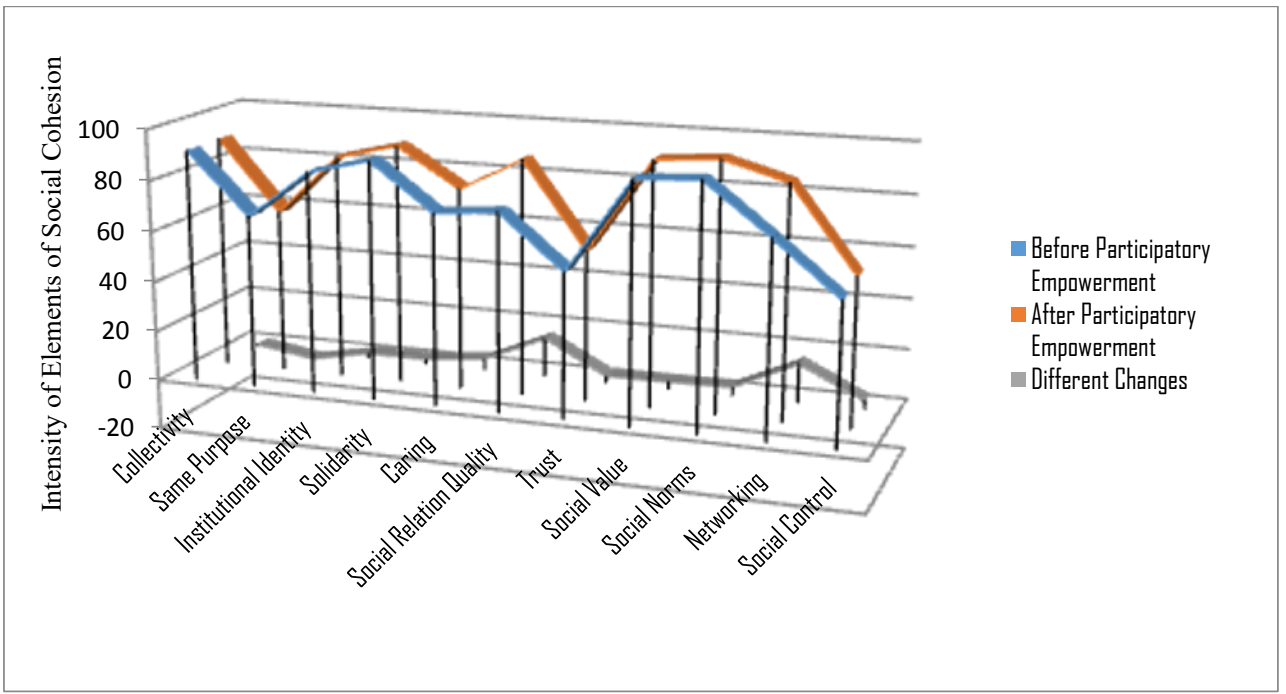

Fig 4. The function of social cohesion elements at the institutional level

Social cohesion at the institutional level has several elements that function to support participatory empowerment. The function of elements is more dominant in the interests of social activities such as helping, voluntary work, and cooperation. The function of social cohesion for the benefit of economic activity is still weak, especially before participatory empowerment. Elements that have a weak function, namely a network of economic cooperation, social control and trust. Social values and norms, solidarity and collectivity, function predominantly on the activity of respondents in participatory empowerment. The dominant function of the four elements of social cohesion is not very different between before and after the respondent follows the empowerment of active participation. All elements of social cohesion at the institutional level listed in Figure 4 only make a small difference.

The category of elements of social cohesion that has the dominant function of participatory empowerment at the individual level is a success, trust, quality of social relations, and social values. At the community level, the dominant element of social cohesion is participatory empowerment, namely motives, mentality, actions, and behavior. The element of social cohesion at the institutional level that has the dominant function of participatory empowerment is the network of cooperation and the quality of social relations. Strengthening the function of elements of urgent social cohesion is carried out in a priority starting from the community, individual, and institutional levels. Social cohesion cannot be separated from the success of participatory empowerment in landless peasants. The function of various elements of social cohesion is essential to strengthen and bring closer social relations between landless peasants, as stated by [15]. The strategic value of social cohesion cannot be ignored from every empowerment, including the landless peasants' community. Social cohesion is a vital construction, which is the heart of what is needed by humans in managing and developing various dimensions of life [16].

The results of the research also explain the details of their social cohesion, especially in their shared values, inequality, and quality of life. The function of social cohesion is essential as the axis that ignites the enthusiasm of the respondent and other landless peasants which active in participatory empowerment. Awareness of socio-economic identity drives the motivation of respondents to take decisions and actions to develop diversified productive livelihood patterns. Work as a farm laborer with perseverance as a creative handicraft or craftwork artisan, even as a breeder of freshwater fish in order to help 
them free from the problems of their family economic urgency. This social reality is in line with the results of research $[17,18,19,20]$.

Every element of potential social cohesion is utilized for the participatory empowerment of respondents as peasants in each research village. This social cohesion has strategic functions as a facilitator of entrepreneurial capabilities in agricultural development by maintaining a balance of economic, social, and environmental interests. The limitation on the ownership of fertile agricultural arable land causes some respondents to lose their motivation to work as peasants. Respondents' abilities regarding verticulture, hydroponic, aquaponic, and aeroponic technologies that are environmentally friendly and can be applied to yards with narrow land are still meager. Meanwhile, respondents experienced some severe problems when they switched to non-farm jobs because of their agrarian oriented behavior of work. The issue of job conversion from on-farm to non-farm could be overcome by utilizing elements of social cohesion at the individual, community and institutional level that directs peasants to have the ability to create a multiple livelihoods pattern at the same time while being in the on-farm, off-farm or even in a non-farm condition. Social, economic, and environmental cohesion values have an essential value for increasing their entrepreneurial spirit that supports the management of agricultural enterprises [21]. Enhancing social cohesion through a comprehensive policy package is crucial to sustainable poverty reduction [22]. Cohesive communities are more able to fight together with integrity based on social capital with a shared sense of belonging.

\section{Result and Discussion}

Social cohesion within landless peasants is distinguished according to both to individual, community, and institutional levels. The dominance of social cohesion at the community level is much stronger than the participatory empowerment of landless peasants in their individual and institutional levels. Some elements of social cohesion have been categorized at each level. The condition of the elements of social cohesion before and after participatory empowerment shows a different level of function. Landless peasants have also made adjustments to the elemental functions of social cohesion during their participatory empowerment.

The categorization of elements of social cohesion shows that at the level of individuals there is some dominant experience increase especially in enthusiasm, trust, quality, closeness of social relations, solidarity and social values, while the increase in the cohesion of social elements at the dominant community level is within their motive, mentality, action, behavior, awareness of self-identity and morality. There are also some slight increases in the element of social cohesion at the institutional level, namely the quality of social relations and collaboration networks. All the elements of social cohesion that have a dominant increase contribute significantly to the participatory empowerment of peasants within the community.

The use of elements in social cohesion needs to be considered while launching the participant empowerment of peasants. The management strategy for the function of elements of social cohesion at the individual, community, and institutional level requires an adaptive approach. Further research still needs to be done to examine the appropriate method model for the management of elements within social cohesion in order creates an ability of optimal function for the empowerment of peasants.

\section{Acknowledgment}


Thank you to the Directorate of Research and Community Service. Directorate General of Research and Development Strengthening. The Ministry of Research, Technology and Higher Education of the Republic of Indonesia has provided research grants to the research team. The research grant was given, including the category of centralization of basic research schemes in the first phase of the 2019 period.

\section{References}

[1] R. Harini, H.S. Yunus, Kasto, S. Hartono. Indonesian J. Geography. Vol 44 (2). (2012)

[2] D. Dumasari, B. Dharmawan, I. Santosa, W. Darmawan, P. Utami, D.D. Aisyah. J. Arts Humanit. (2019)

[3] Q. U. A. Memon, S. A. Wagan, D. Chunyu, X. Shuangxi, and L. Jingdong, J. Poverty 23, 269 (2019)

[4] M. Rondhi, P. Pratiwi, V. Handini, A. Sunartomo, and S. Budiman, Land 7, 148 (2018)

[5] J. Zhao. Thesis. University of Waterloo, China (2017)

[6] C. A. Francis, T. E. Hansen, A. A. Fox, P. J. Hesje, H. E. Nelson, A. E. Lawseth, and A. English, Int. J. Agric. Sustain. 10, 8 (2012)

[7] T. H. T. Nguyen, V. T. Tran, Q. T. Bui, Q. H. Man, and T. de V. Walter, Land Use Policy 54, 583 (2016)

[8] L. Han, H. Bao, and Y. Peng, Sustainability 9, 1158 (2017)

[9] P. W. Speer, C. B. Jackson, and N. A. Peterson, Heal. Educ. Behav. 28, 716 (2001)

[10] S. Martin, K. Lorenzen. World Development J. Vol 83. (2016)

[11] M. Berhe, D. Hoag, G. Tesfay, T. Tadesse, S. Oniki, M. Kagatsume, and C. M. H. Keske, Pastoralism 7, 12 (2017)

[12] D. Dumasari, W. Darmawan, A. Iqbal, B. Dharmawan, and I. Santosa, Int. J. Adv. Sci. Eng. Inf. Technol. 9, 717 (2019)

[13] J. W. Creswell, Qualitative Enquiry \& Research Design, Choosing among Five Approaches (2007)

[14] M.B. Miles, A.M. Mac Graw Hill Company, New York (1991)

[15] S. N. Mulunga and R. Yazdanifard, Glob. J. Manag. Bus. Res. (2014)

[16] X. Fonseca, S. Lukosch, F. Brazier. J. Social Science Research. Vol 32 (2). (2019)

[17] D. Pugersari, A. Syarief, and D. Larasati. J. Arts and Design. (2013)

[18] Y. Fu, in Proc. 2015 Int. Conf. Arts, Des. Contemp. Educ. (Atlantis Press, Paris, France, 2015)

[19] D. Dumasari, S. Budiningsih, W. Darmawan, and I. Santosa, J. Arts Humanit. 6, 01 (2017)

[20] J. Fengfan, J. Arts Humanit. 6, 12 (2017)

[21] E. Hudcová, T. Chovanec, and J. Moudrý, Eur. Countrys. 10, 377 (2018)

[22] A. Kolev, (2015) 